\title{
Front Matter: Volume 11184
}

, "Front Matter: Volume 11184," Proc. SPIE 11184, Optoelectronic Devices and Integration VIII, 1118401 (25 November 2019); doi: 10.1117/12.2560497

SPIE. Event: SPIE/COS Photonics Asia, 2019, Hangzhou, China 


\title{
PROCEEDINGS OF SPIE
}

\section{Optoelectronic Devices and Integration VIII}

\author{
Xuping Zhang \\ Baojun Li \\ Changyuan Yu \\ Xinliang Zhang \\ Daoxin Dai \\ Editors
}

\section{2-23 October 2019 \\ Hangzhou, China}

\author{
Sponsored by \\ SPIE \\ COS-Chinese Optical Society
}

\section{Cooperating Organizations}

Tsinghua University (China) • Peking University (China) • University of Science and Technology of China (China) • Zhejiang University (China) - Tianjin University (China) - Beijing Institute of Technology (China) • Beijing University of Posts and Telecommunications (China) - Nankai University (China) - Changchun University of Science and Technology (China) University of Shanghai for Science and Technology (China) • Capital Normal University (China) • Huazhong University of Science and Technology (China) - Beijing Jiaotong University (China) • China Jiliang University (China) - Shanghai Institute of Optics and Fine Mechanics, CAS (China) - Changchun Institute of Optics, Fine Mechanics and Physics, CAS (China) Institute of Semiconductors, CAS (China) • Institute of Optics and Electronics, CAS (China) • Institute of Physics, CAS (China) Shanghai Institute of Technical Physics, CAS (China) • China Instrument and Control Society (China) • Japan Optical Society (Japan) - Korea Optical Society (Korea, Republic of) • Australia Optical Society (Australia) • Singapore Optical Society (Singapore) • European Optical Society

Supporting Organizations

China Association for Science and Technology (CAST)

Department of Information of National Nature Science Foundation, China (NSFC)

Published by

SPIE

Volume 11184 
The papers in this volume were part of the technical conference cited on the cover and title page. Papers were selected and subject to review by the editors and conference program committee. Some conference presentations may not be available for publication. Additional papers and presentation recordings may be available online in the SPIE Digital Library at SPIEDigitallibrary.org.

The papers reflect the work and thoughts of the authors and are published herein as submitted. The publisher is not responsible for the validity of the information or for any outcomes resulting from reliance thereon.

Please use the following format to cite material from these proceedings:

Author(s), "Title of Paper," in Optoelectronic Devices and Integration VIII, edited by Xuping Zhang, Baojun Li, Changyuan Yu, Xinliang Zhang, Daoxin Dai, Proceedings of SPIE Vol. 11184 (SPIE, Bellingham, WA, 2019) Seven-digit Article CID Number.

ISSN: 0277-786X

ISSN: 1996-756X (electronic)

ISBN: 9781510630857

ISBN: 9781510630864 (electronic)

Published by

SPIE

P.O. Box 10, Bellingham, Washington 98227-0010 USA

Telephone +1 3606763290 (Pacific Time) · Fax + 13606471445

SPIE.org

Copyright @ 2019, Society of Photo-Optical Instrumentation Engineers.

Copying of material in this book for internal or personal use, or for the internal or personal use of specific clients, beyond the fair use provisions granted by the U.S. Copyright Law is authorized by SPIE subject to payment of copying fees. The Transactional Reporting Service base fee for this volume is $\$ 21.00$ per article (or portion thereof), which should be paid directly to the Copyright Clearance Center (CCC), 222 Rosewood Drive, Danvers, MA 01923. Payment may also be made electronically through CCC Online at copyright.com. Other copying for republication, resale, advertising or promotion, or any form of systematic or multiple reproduction of any material in this book is prohibited except with permission in writing from the publisher. The CCC fee code is 0277$786 \times / 19 / \$ 21.00$.

Printed in the United States of America by Curran Associates, Inc., under license from SPIE.

Publication of record for individual papers is online in the SPIE Digital Library.

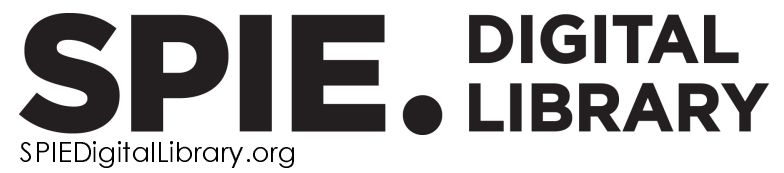

Paper Numbering: Proceedings of SPIE follow an e-First publication model. A unique citation identifier (CID) number is assigned to each article at the time of publication. Utilization of CIDs allows articles to be fully citable as soon as they are published online, and connects the same identifier to all online and print versions of the publication. SPIE uses a seven-digit CID article numbering system structured as follows:

- The first five digits correspond to the SPIE volume number.

- The last two digits indicate publication order within the volume using a Base 36 numbering system employing both numerals and letters. These two-number sets start with $00,01,02,03,04$, 05, 06, 07, 08, 09, OA, OB ... 0Z, followed by 10-1Z, 20-2Z, etc. The CID Number appears on each page of the manuscript. 


\title{
Contents
}

\author{
vii Authors \\ ix Symposium Committees \\ xiii Conference Committee
}

SESSION 1 OPTOELECTRONIC DEVICES AND INTEGRATION I

1118405 A six-channel wavelength-mode-division multiplexer/demultiplexer based on photonic crystals [1 $11184-4]$

\section{SESSION 2 OPTOELECTRONIC DEVICES AND INTEGRATION II}

1118408 Large-scale wavelength multi/demultiplexer using a spatial grating combined with arrayed waveguide gratings [ $111184-7$ ]

1118409 Comparison of fabrication tolerance of broadband silicon photonic directional couplers [11184-8]

SESSION $3 \quad$ OPTOELECTRONIC DEVICES AND INTEGRATION III

11184 OC High performance and CMOS compatible photonic switches based on phase change materials (Invited Paper) [1 $11184-11$ ]

11184 OF Design of a hybrid wavelength selective switch using silica and silicon waveguides [1 $1184-14]$

$111840 \mathrm{OG}$ Limited propagation and nanofocusing of radially polarized light through hybrid plasmonic waveguide [1 $11184-15]$

SESSION 4 OPTOELECTRONIC DEVICES AND INTEGRATION IV

$111840 \mathrm{Ol} \quad$ Recent advances in dispersion engineering for mid-infrared photonics (Invited Paper) [11184-17]

11184 OK A silicon-graphene hybrid waveguide photodetector with a 3dB-bandwidth of $17 \mathrm{GHz}$ [11184-19] 
11184 OM Analysis of red-shift in SMFP-LD with positive and negative wavelength detuning [1 1184-22]

11184 ON AllnGaAs MQWs photonic integration device with directional coupler for multifunction of light emission/detection in infrared range [11184-23]

1118400 A bonded template-assisted monolithic integration platform (Invited Paper) [11184-20]

\section{SESSION $6 \quad$ OPTOELECTRONIC DEVICES AND INTEGRATION VI}

$111840 Q \quad$ Ultra-broadband photodetector based on three-dimensional graphene [11184-27]

$11184 \mathrm{OR} \quad$ An ion-ion interaction analysis-based performance estimation of thulium-doped fiber amplifiers in s-band including amplified spontaneous emission [11184-28]

\section{SESSION $7 \quad$ OPTOELECTRONIC DEVICES AND INTEGRATION VII}

11184 OT Low-cost, high-performance VR delay detection device based on PIN photodiode [1 1 184-30]

11184 OU Demonstration of RF multiplier using an injection-locked laser with OEO [1 $11184-31$ ]

11184 OW Study on the tail in TDOE of the coated MCP-PMT and its suppression [1 $11184-33]$

POSTER SESSION

$111840 \mathrm{X}$ Compact confinement of radially polarized light in graphene cylindrical hybrid plasmonic waveguide [1 $11184-34]$

11184 OY The systematic analysis of epitaxial self-assembled GaN/AIN QDs in S-K method by MOCVD [11 1 184-35]

$111840 Z$ Image characteristics and restoration for multi-sub-mirror synthetic aperture system [1 11 184-36]

$1118410 \quad$ Nearly arbitrary pulse shaping in mode-locked gain-modulated SOA-fibre laser [11184-37]

$1118411 \quad$ Numerical simulation of the effects of InAISb barrier layers on the InSb mid-infrared photodetectors on a mismatched substrate [1 $11184-38]$

1118412 A SOI waveguide grating coupler enhanced by additional silicon nitride layer [1 1184-39]

iv 
1118413 Research on $\mathbf{1 \times 4}$ polarization-independent beam splitter based on silicon waveguide [1 $1184-40]$

$1118414 \quad$ New method of wavelength stabilisation in CPT atomic clocks [1 $1184-41]$

$1118415 \quad$ LIBS underwater precision positioning system [1 $1184-42]$

$1118416 \quad$ Resistive switching memory devices based on PbS quantum dots [1 $1184-43]$

1118417 Transparent nanostructured ZnS films by low temperature sputtering for flexible optoelectronic devices [11184-44]

1118418 Microring lasers based on $\mathrm{Si}_{3} \mathrm{~N}_{4}$ optical waveguides cladded with perovskite quantum dot film [11184-45] 
Proc. of SPIE Vol. $111841118401-6$

Downloaded From: https://www.spiedigitallibrary.org/conference-proceedings-of-spie on 25 Apr 2023 Terms of Use: https://www.spiedigitallibrary.org/terms-of-use 


\title{
Authors
}

Numbers in the index correspond to the last two digits of the seven-digit citation identifier (CID) article numbering system used in Proceedings of SPIE. The first five digits reflect the volume number. Base 36 numbering is employed for the last two digits and indicates the order of articles within the volume. Numbers start with 00, 01, 02, 03, 04, 05, 06, 07, 08, 09, OA, OB...0Z, followed by 10-1Z, 20-2Z, etc.

\author{
Ali, Nadir, OC \\ Andryushkov, Valerii, 14 \\ Bai, Bing, 12 \\ Bassi, Snehi, OM, OU \\ Beausoleil, Raymond G., 00 \\ Bu, Jin, OG \\ Chen, Hao, OM, OU \\ Chen, Heming, 05, 13 \\ Chen, Hongda, 12 \\ Chen, Lin, OW \\ Chen, Xiangning, 09 \\ Chen, Zhiliang, 0Q, 16 \\ Cheng, Chuantong, 12 \\ Cheng, Kai, 15 \\ Dai, Daoxin, OK, 18 \\ Fan, Lixing, OW \\ Gao, Tianxi, 12 \\ Guan, Jian Fei, $\mathrm{OZ}$ \\ Guo, Jingshu, OK \\ Guo, Yuhao, 01 \\ $\mathrm{Hao}$, Weiqian, $\mathrm{OZ}$ \\ $\mathrm{He}$, Sizhen, OX \\ $\mathrm{Hu}$, Wenliang, OY \\ $\mathrm{Hu}$, Yingtao, $0 \mathrm{O}$ \\ Huang, Beiju, 12 \\ Ivanenko, Aleksey, 10 \\ Jafari, Zeinab, ol \\ Jia, Bowen, 11 \\ Jiang, Qiuyang, 09 \\ Jiang, Yan, ON \\ Jin, Lufan, 0Q, 16 \\ Khan, Mohd Mansoor, OR \\ Khripunov, Sergey, 14 \\ Kobayashi, Kunio, OF \\ Kobtsev, Sergey, 10, 14 \\ Kong, Meimei, $\mathrm{OZ}$ \\ Kumar, Rajesh, OC \\ Kurczveil, Geza, 00 \\ Li, Jiang, OK \\ $\mathrm{Li}$, Jie, $0 Q$ \\ Li, Kang, OG, OX \\ Li, Qingyan, $0 Q$
}

\author{
Li, Tengteng, $O Q$ \\ $\mathrm{Li}, \mathrm{Xin}, \mathrm{ON}$ \\ Li, Yifan, 0Q, 16 \\ Li, Yuanjie, 17 \\ Liang, Di, 00 \\ Liang, Zhongcheng, OX, OZ \\ Liu, Chaoyue, OK \\ Liv, Erhu, 18 \\ Liv, Henan, 01 \\ Liu, Jun, 15 \\ Liu, Lianxiang, 05 \\ Liu, Xiaoyao, $0 Z$ \\ Lu, Xinyi, OX \\ Ma, LU, OG \\ Meng, Linghai, 18 \\ Muhammad, Shoaib, 17 \\ Nakarmi, Bikash, OM, OU \\ $\mathrm{Ni}$, Shuyu, ON \\ Ning, Lei, OT \\ Nyushkov, Boris, 10 \\ Ohori, Akihisa, 08 \\ Pan, Shilong, OM, OU \\ Qi, Zhiqiang, OY \\ Qian, XU, 11 \\ Radnatarov, Daba, 14 \\ Shan, Xiaotao, 12 \\ Shen, Lingbin, OW \\ Singh, Shubham, 0C \\ Smirnov, Sergey, 10 \\ Sonkar, Ramesh Kumar, OR \\ Sun, Haocheng, OY \\ Tao, Guangfan, 09 \\ Tian, Jinshou, OW \\ Tian, Liping, OW \\ Tsuda, Hiroyuki, 08, OF \\ Wang, Bowen, 11 \\ Wang, Jing, 0 I \\ Wang, Wei, ON \\ Wang, Xingchao, OW \\ Wang, Yongjin, ON \\ Wu, Chao, 17 \\ Xiang, Yuluan, 18
}


$X u, J i, ~ O G, O X$

$X U$, Lijuan, 0 I

$X u$, Shuang, 15

Xu, Xiaobo, 12

Yan, Shi, OT

Yang, Yang, OT

Yao, Jianquan, $0 Q, 16$

Yin, Yanlong, OK

YU, YU, OQ, 16

Yuan, Jialei, $\mathrm{ON}$

Zarudnev, Yurii, 14

Zhang, Lei, OT

Zhang, Limin, OM, OU

Zhang, Lin, Ol

Zhang, Sicheng, OG, OX

Zhang, Yating, $O Q, 16$

Zhang, Yue, $\mathrm{OZ}$

Zhang, Zan, 12

Zhang, Zanyun, 12

Zhang, Zhengman, 13

Zhao, Hongliang, $0 Q$

Zhao, Rui, OZ

Zhao, Zhiqin, 11

Zhong, Haizheng, 18

Zhou, Yi, OG

Zhu, Xuan, 17 


\title{
Symposium Committees
}

\author{
General Chairs
}

Jim M. Oschmann, President, SPIE and Ball Aerospace (United States)

Qihuang Gong, President, Chinese Optical Society and Peking University (China)

General Co-chairs

Guangcan Guo, Past President, Chinese Optical Society and University of Science and Technology of China (China)

Zejin Liu, Vice President, Chinese Optical Society and National University of Defense Technology (China)

Technical Program Chairs

Ruxin Li, Vice President, Chinese Optical Society and Shanghai Institute of Optics and Fine Mechanics (China)

Xingde Li, Johns Hopkins University (United States)

Technical Program Co-chairs

Tianchu Li, National Institute of Metrology (China)

Wei Huang, Northwestern Polytechnical University (China)

Ying Gu, Vice President, Chinese Optical Society and PLA General Hospital (China)

Huilin Jiang, Changchun University of Science and Technology (China)

Wenqing Liu, Vice President, Chinese Optical Society, and Anhui Institute of Optics and Fine Mechanics (China)

Guobin Fan, China Academy of Engineering Physics (China)

Suotang Jia, Vice President, Chinese Optical Society, and Shanxi University (China)

Xiaomin Ren, Vice President, Chinese Optical Society, and Beijing University of Posts and Telecommunications (China)

Secretaries-General

Bo Gu, Deputy Secretary General, Chinese Optical Society (China)

Hong Yang, Deputy Secretary General, Chinese Optical Society and Peking University (China) 
Yan Li, Deputy Secretary General, Chinese Optical Society, and Peking University (China)

Daoxin Dai, Zhejiang University (China)

Local Organizing Committee Chair

Xu Liu, Secretary General, Chinese Optical Society and Zhejiang University (China)

Local Organizing Committee Co-chairs

Jianrong Qiu, Zhejiang University (China)

Daoxin Dai, Zhejiang University (China)

Local Secretaries

Wei Xiong, Chinese Optical Society (China)

Qing Yang, Zhejiang University (China)

Local Organizing Committee

Qing Yang, Zhejiang University (China)

Lan Wu, Zhejiang University (China)

Yaocheng Shi, Zhejiang University (China)

Dong Liu, Zhejiang University (China)

Yungui Ma, Zhejiang University (China)

Ke Si, Zhejiang University (China)

Yang Yang, Zhejiang University (China)

Xinyong Dong, China Jiliang University (China)

Le Wang, China Jiliang University (China)

Fei Tong, Chinese Optical Society (China)

Technical Organizing Committee

Mohammad Hossein Asghari, Loyola Marymount University

(United States) and Tachyonics Inc. (United States)

Pablo Benítez, Universidad Politécnica de Madrid (Spain)

Liangcai Cao, Tsinghua University (China)

P. Scott Carney, University of Rochester (United States)

Benyong Chen, Zhejiang University of Science and Technology

(China)

Hongqiang Chen, GE Global Research (United States)

Daoxin Dai, Zhejiang University (China)

Qionghai Dai, Tsinghua University (China)

Qihuang Gong, Peking University (China)

Ying Gu, Chinese PLA General Hospital (China) 
Guang-Can Guo, University of Science and Technology of China (China)

Byoung Seung Ham, Gwangju Institute of Science and Technology (Korea, Republic of)

Sen Han, University of Shanghai for Science and Technology (China) and Suzhou H\&L Instruments, LLC (China)

Zuyuan He, Shanghai Jiao Tong University (China)

Werner H. Hofmann, Technische Universität Berlin (Germany)

Minghui Hong, National University of Singapore (Singapore)

Bahram Jalali, University of California, Los Angeles (United States)

Satoshi Kawata, Osaka University (Japan)

Baojun Li, Jinan University (China)

Ming Li, Institute of Semiconductors, CAS (China)

Ruxin Li, Shanghai Institute of Optics and Fine Mechanics (China)

Xingde Li, Johns Hopkins University (United States)

Jian Liu, PolarOnyx, Inc. (United States)

Tiegen Liu, Tianjin University (China)

Yongfeng Lu, University of Nebraska-Lincoln (United States)

Qingming Luo, Huazhong University of Science and Technology (China)

Gang-Ding Peng, The University of New South Wales (Australia)

Osamu Matoba, Kobe University (Japan)

Min Qiu, Westlake University (China)

Yuji Sano, ImPACT (Japan)

Yunlong Sheng, Université Laval (Canada)

Kebin Shi, Peking University (China)

Tsutomu Shimura, The University of Tokyo (Japan)

Upendra N. Singh, NASA Langley Research Center (United States)

Michael G. Somekh, Shenzhen University (China)

Yuguo Tang, Suzhou Institute of Biomedical Engineering and

Technology (China)

Masahiko Tani, University of Fukui (Japan)

Limin Tong, Zhejiang University (China)

Kazumi Wada, Massachusetts Institute of Technology (United States)

Yongtian Wang, Beijing Institute of Technology (China)

Rongshi Xiao, Beijing University of Technology (China)

Hongxing $\mathrm{Xu}$, Wuhan University (China)

Jianhua Yao, Zhejiang University of Technology (China)

Toru Yoshizawa, Tokyo University of Agriculture and Technology (Japan) and 3D Associates, Inc. (Japan)

Changyuan Yu, The Hong Kong Polytechnic University (Hong Kong, China)

Xiao-Cong Yuan, Shenzhen University (China)

Cunlin Zhang, Capital Normal University (China)

Song Zhang, Purdue University (United States)

Xi-Cheng Zhang, University of Rochester (United States) 
Xinliang Zhang, Wuhan National Laboratory for Optoelectronics (China)

Xuping Zhang, Nanjing University (China)

Zhenrong Zheng, Zhejiang University (China)

Changhe Zhou, Shanghai Institute of Optics and Fine Mechanics (China)

Zhiping Zhou, Peking University (China)

Dan Zhu, Huazhong University of Science and Technology (China)

Ning Hua Zhu, Institute of Semiconductors, CAS (China) 


\title{
Conference Committee
}

\author{
Conference Chairs
}

Xuping Zhang, Nanjing University (China)

Baojun Li, Jinan University (China)

Changyuan Yu, The Hong Kong Polytechnic University

(Hong Kong, China)

Xinliang Zhang, Wuhan National Laboratory for Optoelectronics

(China)

Conference Co-chair

Daoxin Dai, Zhejiang University (China)

Conference Program Committee

Dayan Ban, University of Waterloo (Canada)

Zhongping Chen, Beckman Laser Institute and Medical Clinic (United States)

Ho-Pui Ho, The Chinese University of Hong Kong (Hong Kong, China)

Jan Ingenhoff, lonexphotonics Inc. (Canada)

Zhongcheng Liang, Nanjing University of Posts and Telecommunications (China)

Xuejun Lu, University of Massachusetts Lowell (United States)

Ali Masoudi, University of Southampton (United Kingdom)

Hai Ming, University of Science and Technology of China (China)

Gang-Ding Peng, The University of New South Wales (Australia)

Yaocheng Shi, Zhejiang University (China)

Yuan Shi, Agilecom Photonic Solutions Inc. (United States)

Anna K. Swan, Boston University (United States)

Frank Vollmer, Max-Planck-Institut für die Physik des Lichts (Germany)

Daniel M. Wasserman, The University of Texas at Arlington

(United States)

Lixin Xu, University of Science and Technology of China (China)

Yang Yang, Zhejiang University of Technology (China)

Ningmu Zou, Advanced Micro Devices, Inc. (United States)

\section{Session Chairs}

1 Optoelectronic Devices and Integration I

Daoxin Dai, Zhejiang University (China)

Jianwei Wang, Peking University (China) 
2 Optoelectronic Devices and Integration II

Daoxin Dai, Zhejiang University (China)

Wei Jiang, Nanjing University (China)

3 Optoelectronic Devices and Integration III

Vilson Rosa Almeida, Instituto Tecnológico de Aeronáutica (Brazil)

Changyuan Yu, The Hong Kong Polytechnic University (Hong Kong, China)

4 Optoelectronic Devices and Integration IV

Xinliang Zhang, Wuhan National Laboratory for Optoelectronics (China)

Di D. Liang, Hewlett Packard Enterprise (United States)

5 Optoelectronic Devices and Integration V

Xinliang Zhang, Wuhan National Laboratory for Optoelectronics (China)

Lin Zhang, Tianjin University (United States)

6 Optoelectronic Devices and Integration VI

Changyuan Yu, The Hong Kong Polytechnic University (Hong Kong, China)

Lei Bi, University of Electronic Science and Technology of China (China)

7 Optoelectronic Devices and Integration VII

Changyuan Yu, The Hong Kong Polytechnic University (Hong Kong, China)

Yuqing Jiao, Technische Universiteit Eindhoven (Netherlands) 